\title{
Association Between Body Mass Index and Severe Infection in Anti-Neutrophil Cytoplasmic Antibody- Associated Vasculitis: A Retrospective Cohort in Japan
}

Hirokazu Sugiyama

Aichi Medical University

Makoto Yamaguchi

Aichi Medical University

Takayuki Katsuno

Aichi Medical University

Hironobu Nobata

Aichi Medical University

Shiho Iwagaitsu

Aichi Medical University

Hiroshi Kinashi

Aichi Medical University

Shogo Banno

Aichi Medical University

Takuji Ishimoto

Nagoya University

Yasuhiko Ito ( $\nabla$ yasuito@aichi-med-u.ac.jp )

Aichi Medical University https://orcid.org/0000-0002-9676-6961

Research article

Keywords: Antibodies, Antineutrophil Cytoplasmic Antibody-Associated Vasculitis, Body Mass Index, Infection

Posted Date: September 22nd, 2020

DOI: https://doi.org/10.21203/rs.3.rs-77519/v1

License: (1) (1) This work is licensed under a Creative Commons Attribution 4.0 International License. Read Full License 
Version of Record: A version of this preprint was published on March 9th, 2021. See the published version at https://doi.org/10.1186/s12877-021-02123-y. 


\section{Abstract}

Background: Although previous studies have evaluated risk factors for the incidence of severe infection in patients with antineutrophil cytoplasmic antibody-associated vasculitis (AAV), the relationship between body mass index (BMI) and severe infection in AAV has not been elucidated. We hypothesized that elderly AAV patients with a low BMI would be at a higher risk of infection. To evaluate this hypothesis, we investigated the association between underweight at AAV diagnosis and subsequent severe infection in elderly AAV patients.

Methods: This single-center retrospective cohort study included 98 consecutive elderly AAV patients treated at the Aichi Medical University Hospital in Japan between 2004 and 2018. The relationships between $\mathrm{BMI}$ at diagnosis and subsequent first severe infection were assessed using multivariate Cox proportional hazards models.

Results: During the entire follow-up period (median, 22 months; interquartile range, 7-52 months), 32 (32.7\%) patients developed at least one severe infection. Low BMI $\left(<18.5 \mathrm{~kg} / \mathrm{m}^{2}\right.$ compared with normal BMI [18.5-23.0 kg/m²], adjusted hazard ratio [HR] = 2.70, 95\% confidence interval [Cl]: $1.18-6.17 ; P=$ 0.018 ) and use of methylprednisolone pulse therapy (adjusted $\mathrm{HR}=3.09,95 \% \mathrm{Cl}: 1.37-6.99 ; P=0.007$ ) were the significant predictors of severe infection. Furthermore, an interaction effect between unintentional body weight loss $(>10 \%)$ within 6 months before diagnosis and low BMI was observed $(\mathrm{P}<$ $0.001)$.

Conclusions: Low BMI was associated with a higher risk of severe infection in elderly AAV patients, suggesting that careful management may be required to prevent the development of infection in patients with a low BMI. Further studies are needed to elucidate the optimal treatment strategy for these patients.

\section{Background}

Antineutrophil cytoplasmic antibody (ANCA)-associated vasculitis (AAV) is characterized by necrotizing vasculitis of the small vessels and high ANCA-positivity; the condition includes microscopic polyangiitis (MPA), granulomatosis with polyangiitis (GPA), and eosinophilic granulomatosis with polyangiitis (EGPA) $[1,2]$.

Recently, avoidance of fatal organ damage in AAV has been achieved by advances in the treatment strategy for AAV [3-7]. However, patients with AAV have markedly higher rates of severe infection than the general population, and infection is an important complication, associated with morbidity and mortality, that occurs during immunosuppressive treatment for AAV [8].

Previous studies have identified several risk factors for development of infection in AAV; these include the use of high-dose and higher cumulative exposure to glucocorticoids, the use of immunosuppressive agents, older patient age, leukopenia or lymphopenia, and kidney dysfunction [8-18]. 
Body mass index (BMI) has been regarded as an indicator of nutritional issues; malnutrition can lead to underweight, while overnutrition can lead to overweight [19]. To date, although the association between $\mathrm{BMI}$ and the incidence of infection has been evaluated in several general population-based observational studies [19-28], the results, according to the participants' characteristics, were inconsistent. Furthermore, no previous studies have focused on patients who are immunocompromised due to immunosuppressive treatment, including patients with AAV. Therefore, the clinical impact of BMI on the incidence of infection in AAV patients receiving immunosuppressive therapy remained unknown.

In the present study, we hypothesized that elderly AAV patients with a low BMI would be at a higher risk of development of infection. To evaluate this hypothesis, we investigated the association between underweight at the diagnosis of AAV and subsequent severe infection in elderly AAV patients, using a single-center, retrospective cohort from Japan.

\section{Methods}

\section{Study population}

The present study included 126 adult patients who were diagnosed with AAV, including GPA, MPA, and EGPA, based on the classification of the AAV by the European Medicines Agency algorithm [29], at Nephrology and Rheumatology centers in the Aichi Medical University in Japan between 2004 and 2018. After excluding 28 patients (22.2\%) who were non-elderly (aged < 65 years; $n=20$ ), were not on immunosuppressive therapy $(n=2)$, and those with missing BMI data $(n=6), 98$ patients $(77.8 \%)$ who received immunosuppressive therapy were included in the present study (Fig. 1).

The study protocol was approved by the Ethics Committees of Aichi Medical University (approval number 2018-H350, date November 3, 2019). The need to obtain patients' informed consent was waived due to the retrospective nature of the study.

Data collection

Baseline characteristics, at the start of immunosuppressive therapy, were collected retrospectively from patients' medical records and included the following: age; sex; BMl; body weight loss $>10 \%$ within 6 months before diagnosis; serum creatinine level; serum albumin level; C-reactive protein level; serum IgG level; presence of diabetes mellitus; Birmingham Vasculitis Activity Score (BVAS) 2003 [30]; organ involvement; anti-myeloperoxidase (MPO) and anti-proteinase 3 (PR3) ANCA levels; use of immunosuppressive treatment, such as induction immunosuppressive therapy; methylprednisolone pulse therapy ( 0.5 or $1.0 \mathrm{~g} /$ day for 3 consecutive days); intravenous cyclophosphamide (CYC) or rituximab (RTX) use, and maintenance therapy; oral CYC use, azathioprine (AZA) use, methotrexate use, and RTX use.

All serum samples were tested by direct antigen-specific enzyme-linked immunosorbent assays for MPO and PR3-ANCA, using serial serum dilutions, as previously described [31]. The samples were diluted 1:500 
(Nipro Medical Corporation, Osaka, Japan) or 1:101 (Medical and Biological Laboratories Co., Ltd., Nagoya, Japan).

\section{Outcomes}

The primary exposure of interest was the BMI at the diagnosis of AAV. BMI was defined according to the World Health Organization Asian Standard [32]; underweight was defined as BMl $<18.5 \mathrm{~kg} / \mathrm{m}^{2}$, normal weight as BMI $18.5-22.9 \mathrm{~kg} / \mathrm{m}^{2}$, overweight as BMI $23.0-24.9 \mathrm{~kg} / \mathrm{m}^{2}$, obesity I (moderate obesity) as BMI $25.0-29.9 \mathrm{~kg} / \mathrm{m}^{2}$, and obesity II (severe obesity) as BMI $\geq 30 \mathrm{~kg} / \mathrm{m}^{2}$. Because of the small number of overweight, obesity I and II patients, we combined these three groups into a "high BMI" group. Accordingly, we stratified patients into three BMl categories: low BMI (BMI $\left.<18.5 \mathrm{~kg} / \mathrm{m}^{2}\right)$, normal BMI (BMI 18.5$\left.23 \mathrm{~kg} / \mathrm{m}^{2}\right)$, and high BMl (BMl $\left.>23 \mathrm{~kg} / \mathrm{m}^{2}\right)$.

The main outcome of interest was the development of severe infection, which was defined as infection requiring hospitalization for any causes. Remission was defined as the absence of clinical signs and symptoms of active vasculitis (BVAS $=0$ ) for more than 2 months. Relapse was defined as clinical signs of vasculitic activity in any organ system, followed by an increase in corticosteroid dosing and/or add-on use of immunosuppressive agents after development of remission, as previously described [33]. Other outcome data, including information about end-stage renal disease (ESRD) requiring dialysis, death, and hospitalization due to causes other than infection, was collected. Patients were followed up until December 2019 and data were censored at death or on the last day of attending examination in our hospital before December 2019.

\section{Statistical analyses}

Baseline patient characteristics were summarized according to the three BMI categories, and are presented as a percentage for categorical variables and as median (interquartile range) for continuous variables with both normal and skewed distributions.

The associations of BMI with outcomes were assessed using univariate and multivariate Cox proportional hazards $(\mathrm{CPH})$ models. The multivariate models were adjusted for the following potential confounding factors; age, sex, lung involvement, diabetes mellitus, serum creatinine level, use of methylprednisolone therapy, and BMI (low, normal, and high BMI), based on the clinical experience and theoretical considerations.

Furthermore, we assessed the effect of changes in body weight loss (>10\%) within 6 months before diagnosis and low BMI for the primary outcome in a multivariate model, adjusted for age, sex, lung involvement, diabetes mellitus, serum creatinine level, and use of methylprednisolone therapy. 
The proportional hazard assumption for covariates was tested using scaled Schoenfeld residuals. For continuous variables, the Wilcoxon rank-sum test was used to evaluate the significance of intergroup differences. Categorical variables are expressed as percentages and were compared using the Fisher's exact test. The cumulative probability of the development of a first severe infection was calculated using the Kaplan-Meier method and log-rank test.

The level of statistical significance was set at $P<0.05$. All statistical analyses were performed using JMP, version 14.0.0 (SAS Institute, Cary, NC, USA) and STATA version 13.0 (StataCorp LP, College Station, TX, USA).

\section{Results}

\section{Clinical characteristics}

The baseline characteristics stratified by three BMI categories are shown in Table 1. The present cohort included $23(23.5 \%)$ patients with $\mathrm{BMI}<18.5 \mathrm{~kg} / \mathrm{m}^{2}, 56(57.1 \%)$ patients with BMI $18.5-23.0 \mathrm{~kg} / \mathrm{m}^{2}$, and 19 (19.4\%) patients with $\mathrm{BMI}>23.0 \mathrm{~kg} / \mathrm{m}^{2}$. On comparing the baseline characteristics among the three groups, the proportion of patients with unintentional body weight loss $>10 \%$ within 6 months before diagnosis was significantly higher in the low BMI group than those in the high $B M I$ group $(P=0.003)$. For other baseline characteristics, no significant difference was observed among the three groups. 
Table 1

Clinical characteristics of 98 patients with AAV

\begin{tabular}{|c|c|c|c|c|}
\hline & $\begin{array}{l}\text { Low BMI } \\
(<18.5) \\
(n=23)\end{array}$ & $\begin{array}{l}\text { Normal BMI (18.5- } \\
23.0) \\
(n=56)\end{array}$ & $\begin{array}{l}\text { High BMI } \\
(>23) \\
(n=19)\end{array}$ & $P$ value \\
\hline \multicolumn{5}{|l|}{ Baseline characteristics } \\
\hline Age (years) & $\begin{array}{l}78(68- \\
80)\end{array}$ & $73(69-78)$ & $75(68-78)$ & 0.540 \\
\hline Male sex & $15(65.2)$ & $29(51.8)$ & $8(42.1)$ & 0.314 \\
\hline BMI $\left(k g / m^{2}\right)$ & $\begin{array}{l}17.9 \\
(17.1- \\
18.3)\end{array}$ & $21.0(19.9-22.1)$ & $\begin{array}{l}24.2(23.4- \\
26.2)\end{array}$ & $<0.001$ \\
\hline $\begin{array}{l}\text { Body weight loss }>10 \% \text { within } 6 \\
\text { months before diagnosis }\end{array}$ & $13(56.5)$ & $26(46.4)$ & $4(21.1)$ & 0.003 \\
\hline Serum creatinine level (mg/dL) & $\begin{array}{l}1.4(1.0- \\
6.4)\end{array}$ & $1.6(0.8-3.6)$ & $1.2(0.6-2.2)$ & 0.213 \\
\hline Serum albumin level (mg/dL) & $\begin{array}{l}3.0(2.6- \\
3.2)\end{array}$ & $2.8(2.4-3.3)$ & $3.2(2.5-3.5)$ & 0.569 \\
\hline Serum IgG level (mg/dL) & $\begin{array}{l}1812 \\
(1564- \\
1958)\end{array}$ & $1814(1538-2019)$ & $\begin{array}{l}1734 \text { (1407- } \\
2002)\end{array}$ & 0.508 \\
\hline CRP level (mg/dL) & $\begin{array}{l}6.1(2.6- \\
10.7)\end{array}$ & $3.5(1.1-9.2)$ & $3.9(0.3-12.7)$ & 0.370 \\
\hline Diabetes mellitus & $7(30.4)$ & $9(16.1)$ & $4(21.1)$ & 0.350 \\
\hline Diagnosis & & & & $<0.001$ \\
\hline MPA & $22(95.7)$ & $53(94.6)$ & $18(94.7)$ & 0.982 \\
\hline GPA & $0(0.0)$ & $0(0.0)$ & $0(0.0)$ & \\
\hline EGPA & $1(4.4)$ & $3(5.4)$ & $1(5.3)$ & \\
\hline Antibody & & & & 0.122 \\
\hline MPO-ANCA & $23(100)$ & $56(100)$ & $18(94.7)$ & \\
\hline
\end{tabular}

Continuous data are presented as a median (interquartile range), and categorical data are expressed as a number (proportion).

Abbreviations: BMI, body mass index; MPO, myeloperoxidase; PR3, proteinase-3 ANCA; ANCA, antineutrophil cytoplasmic antibody; AAV, anti-neutrophil cytoplasmic antibody-associated vasculitis; MPA, microscopic polyangiitis; GPA, granulomatosis with polyangiitis; EGPA, eosinophilic granulomatosis with polyangiitis; $\mathrm{mPSL}$, methylprednisolone; HD, hemodialysis; 


\begin{tabular}{|c|c|c|c|c|}
\hline & $\begin{array}{l}\text { Low BMI } \\
\begin{array}{l}(<18.5) \\
(n=23)\end{array}\end{array}$ & $\begin{array}{l}\text { Normal BMI (18.5- } \\
23.0) \\
(n=56)\end{array}$ & $\begin{array}{l}\text { High BMI } \\
(>23) \\
(n=19)\end{array}$ & $P$ value \\
\hline PR3-ANCA & $0(0)$ & $0(0)$ & $1(5.2)$ & \\
\hline BVAS & $\begin{array}{l}15(12- \\
17)\end{array}$ & $14(11-16)$ & $14(11-14)$ & 0.437 \\
\hline \multicolumn{5}{|l|}{ Organ involvement } \\
\hline General & $23(100)$ & $56(100)$ & $18(94.7)$ & 0.122 \\
\hline Cutaneous & $3(13.0)$ & $1(1.8)$ & $2(10.5)$ & 0.111 \\
\hline Ear nose and throat & $7(30.4)$ & $9(16.1)$ & $5(26.3)$ & 0.316 \\
\hline Chest & $6(26.1)$ & $22(39.3)$ & $6(31.6)$ & 0.508 \\
\hline Cardiovascular & $0(0)$ & $0(0)$ & $0(0)$ & 0.000 \\
\hline Abdominal & $1(4.4)$ & $1(1.8)$ & $0(0)$ & 0.599 \\
\hline Renal & $19(82.6)$ & $42(75.0)$ & $14(73.7)$ & 0.729 \\
\hline Nervous system & $5(21.7)$ & $11(19.6)$ & $5(26.3)$ & 0.828 \\
\hline \multicolumn{5}{|l|}{$\begin{array}{l}\text { Induction immunosuppressive } \\
\text { therapy }\end{array}$} \\
\hline mPSL pulse therapy & $12(52.2)$ & $27(48.2)$ & $8(42.1)$ & 0.808 \\
\hline Intravenous cyclophosphamide & $3(13.0)$ & $4(7.1)$ & $1(5.2)$ & 0.600 \\
\hline Rituximab & $1(4.4)$ & $4(7.1)$ & $2(10.5)$ & 0.741 \\
\hline $\begin{array}{l}\text { Maintenance } \\
\text { immunosuppressive therapy }\end{array}$ & & & & 0.336 \\
\hline Glucocorticoid monotherapy & $17(73.9)$ & $39(69.6)$ & $14(73.7)$ & \\
\hline Oral cyclophosphamide & $0(0)$ & $1(1.8)$ & $1(5.3)$ & \\
\hline Azathioprine & $5(21.7)$ & $14(25.0)$ & $2(10.5)$ & \\
\hline Methotrexate & $0(0)$ & $0(0)$ & $0(0)$ & \\
\hline Mizoribine & $1(4.4)$ & $0(0)$ & $0(0)$ & \\
\hline
\end{tabular}

Continuous data are presented as a median (interquartile range), and categorical data are expressed as a number (proportion).

Abbreviations: BMI, body mass index; MPO, myeloperoxidase; PR3, proteinase-3 ANCA; ANCA, antineutrophil cytoplasmic antibody; AAV, anti-neutrophil cytoplasmic antibody-associated vasculitis; MPA, microscopic polyangiitis; GPA, granulomatosis with polyangiitis; EGPA, eosinophilic granulomatosis with polyangiitis; $\mathrm{MPSL}$, methylprednisolone; HD, hemodialysis; 


\begin{tabular}{|c|c|c|c|c|}
\hline & $\begin{array}{l}\text { Low BMI } \\
(<18.5) \\
(n=23)\end{array}$ & $\begin{array}{l}\text { Normal BMI (18.5- } \\
\text { 23.0) } \\
(\mathrm{n}=56)\end{array}$ & $\begin{array}{l}\text { High BMI } \\
\begin{array}{l}(>23) \\
(n=19)\end{array}\end{array}$ & $P$ value \\
\hline Rituximab & $0(0)$ & $2(3.6)$ & $2(10$ & \\
\hline \multicolumn{5}{|l|}{ Outcomes } \\
\hline Remission & $19(82.6)$ & $51(91.1)$ & $17(89.5)$ & 0.553 \\
\hline Relapse & $8(42.1)$ & $19(37.3)$ & $7(41.2)$ & 0.916 \\
\hline Severe infection & $15(65.2)$ & $15(26.8)$ & $2(10.5)$ & $<0.001$ \\
\hline$H D$ & $8(34.8)$ & $11(19.6)$ & $4(21.1)$ & 0.340 \\
\hline Death & $7(30.4)$ & $13(23.2)$ & $2(10.5)$ & 0.030 \\
\hline Infection & $7(100)$ & $6(46.2)$ & $1(50.0)$ & \\
\hline Vasculitis & $0(0)$ & $3(23.1)$ & $0(0)$ & \\
\hline Malignancy & $0(0)$ & $2(15.4)$ & $0(0)$ & \\
\hline Cardiovascular & $0(0)$ & $0(0)$ & $1(50.0)$ & \\
\hline Unknown & $0(0)$ & $2(15.4)$ & $0(0)$ & \\
\hline Observation period (months) & $\begin{array}{l}11(2- \\
51)\end{array}$ & $17(5-43)$ & $28(7-53)$ & 0.489 \\
\hline \multicolumn{5}{|c|}{$\begin{array}{l}\text { Continuous data are presented as a median (interquartile range), and categorical data are expressed } \\
\text { as a number (proportion). }\end{array}$} \\
\hline \multicolumn{5}{|c|}{$\begin{array}{l}\text { Abbreviations: BMI, body mass index; MPO, myeloperoxidase; PR3, proteinase-3 ANCA; ANCA, anti- } \\
\text { neutrophil cytoplasmic antibody; AAV, anti-neutrophil cytoplasmic antibody-associated vasculitis; } \\
\text { MPA, microscopic polyangiitis; GPA, granulomatosis with polyangitis; EGPA, eosinophilic } \\
\text { granulomatosis with polyangiitis; mPSL, methylprednisolone; HD, hemodialysis; }\end{array}$} \\
\hline
\end{tabular}

\section{BMI and severe infection}

During the study period, 39 severe infections occurred in $32(32.7 \%)$ patients. The low BMI category was significantly associated with development of severe infection $(P<0.001)$. The cumulative probabilities of severe infection within 1,2 , and 5 years were, respectively, $0.55,0.59$, and 0.65 for those with low BMl; $0.23,0.31$, and 0.35 for those with normal BMl; and $0.06,0.06$, and 0.16 for those with high BMI. Severe infection differed significantly according to BMI category (log rank, $\mathrm{P}<0.001$; Fig. 2). Causes of infection were tuberculosis pleuritis $(n=1)$, milliary tuberculosis $(n=1)$, cytomegalovirus pneumonia $(n=1)$, influenza pneumonia $(n=1)$, bacterial pneumonia $(n=12)$, fungal pneumonia $(n=4)$, Pneumocystis 
jiroveci pneumonia $(n=2)$, acute colitis $(n=1)$, soft tissue infection $(n=1)$, infectious endocarditis $(n=1)$, vertebral osteomyelitis $(n=1)$, methicillin-resistant Staphylococcus aureus bacteremia $(n=1)$, fungemia $(n=1)$, and acute pyelonephritis $(n=4)$.

\section{Predictors of severe infections}

Predictors of severe infection were evaluated using the clinical data, including age, sex, BMI, serum creatinine level, and use of methylprednisolone pulse therapy on the basis of previous reports [15-18]. Univariate $\mathrm{CPH}$ analyses identified several statistically significant predictors of increased infection risk, namely, older age, use of methylprednisolone pulse therapy, and low BMI (Table 2). Using the multivariate $\mathrm{CPH}$ model, adjusted for age, sex, serum creatinine level, use of methylprednisolone pulse therapy, and BMI, low BMI $\left(<18.5 \mathrm{~kg} / \mathrm{m}^{2}\right.$ compared with normal BMI [18.5-23.0 kg/m²], adjusted hazard ratio [HR] = $2.70,95 \%$ confidence interval [Cl]: 1.18-6.17; $P=0.018$ ) and use of methylprednisolone pulse therapy (adjusted HR $=3.09,95 \% \mathrm{Cl}: 1.37-6.99 ; P=0.007$ ) were identified as the significant predictors of severe infection (Table 2). Furthermore, an interaction effect between unintentional body weight loss $(>10 \%)$ within 6 months before diagnosis and low BMI was observed $(P<0.001)$. 
Table 2

Predictors of first severe infection in AAV

Univariate model

Multivariate model

\begin{tabular}{|c|c|c|c|c|}
\hline & $\mathrm{HR}(95 \% \mathrm{Cl})$ & $P$-value & $\mathrm{HR}(95 \% \mathrm{Cl})$ & $P$-value \\
\hline \multirow[t]{2}{*}{ Age (per 10 years) } & 1.79 & 0.036 & 1.39 & 0.246 \\
\hline & $(1.03-3.10)$ & & $(0.89-1.16)$ & \\
\hline \multirow[t]{2}{*}{ Male (vs. female) } & 1.03 & 0.929 & 1.21 & 0.620 \\
\hline & $(0.51-2.07)$ & & $(0.39-1.74)$ & \\
\hline \multirow[t]{2}{*}{ Lung involvement } & 0.77 & 0.488 & 1.11 & 0.814 \\
\hline & $(0.36-1.62)$ & & $(0.47-2.59)$ & \\
\hline \multirow[t]{2}{*}{ Serum creatinine (per $1.0 \mathrm{mg} / \mathrm{dL}$ ) } & 1.09 & 0.150 & 1.02 & 0.767 \\
\hline & $(0.96-1.21)$ & & $(0.89-1.16)$ & \\
\hline \multirow[t]{2}{*}{ Diabetes mellitus } & 1.10 & 0.815 & 0.44 & 0.085 \\
\hline & $(0.49-2.47)$ & & $(0.18-1.12)$ & \\
\hline \multirow[t]{2}{*}{ mPSL pulse therapy } & 2.81 & 0.007 & 3.09 & 0.007 \\
\hline & $(1.33-5.94)$ & & $(1.37-6.99)$ & \\
\hline \multicolumn{5}{|l|}{ BMI groups } \\
\hline \multirow[t]{2}{*}{ Low BMI $\left(<18.5 \mathrm{~kg} / \mathrm{m}^{2}\right)$} & 2.76 & 0.006 & 2.70 & 0.018 \\
\hline & $(1.34-5.66)$ & & $(1.18-6.17)$ & \\
\hline
\end{tabular}

Data are the $\mathrm{HR}, 95 \% \mathrm{Cl}$, and $P$ value from Cox proportional hazard regression analyses.

The multivariate model was adjusted for the baseline characteristics, including age, sex, lung involvement, serum creatinine level, diabetes mellitus, use of MPSL pulse therapy, and BMI groups (low, normal, and high BMI). "Normal BMI" was used as the reference category.

Abbreviations: BMI, body mass index; $\mathrm{mPSL}$, methylprednisolone, ANCA, anti-neutrophil cytoplasmic antibody; AAV, ANCA-associated vasculitis; HR, hazard ratio; $\mathrm{Cl}$, confidence interval 


\begin{tabular}{|c|c|c|c|}
\hline & Univariate model & \multicolumn{2}{|c|}{ Multivariate model } \\
\hline Normal BMI $\left(18.5-23.0 \mathrm{~kg} / \mathrm{m}^{2}\right)$ & Reference & Refer & \\
\hline \multirow[t]{2}{*}{ High BMI (> $\left.23.0 \mathrm{~kg} / \mathrm{m}^{2}\right)$} & 0.176 & 0.37 & 0.192 \\
\hline & $(0.08-1.58)$ & $(0.08$ & \\
\hline \multicolumn{4}{|c|}{ Data are the $\mathrm{HR}, 95 \% \mathrm{Cl}$, and $P$ value from Cox proportional hazard regression analyses. } \\
\hline \multicolumn{4}{|c|}{$\begin{array}{l}\text { The multivariate model was adjusted for the baseline characteristics, including age, sex, lung } \\
\text { involvement, serum creatinine level, diabetes mellitus, use of mPSL pulse therapy, and BMI groups } \\
\text { (low, normal, and high BMI). "Normal BMI" was used as the reference category. }\end{array}$} \\
\hline \multicolumn{4}{|c|}{$\begin{array}{l}\text { Abbreviations: BMI, body mass index; } \mathrm{mPSL} \text {, methylprednisolone, } \mathrm{ANCA} \text {, anti-neutrophil cytoplasmic } \\
\text { antibody; AAV, ANCA-associated vasculitis; } \mathrm{HR} \text {, hazard ratio; Cl, confidence interval }\end{array}$} \\
\hline
\end{tabular}

\section{Other outcomes}

During the observation period, 19 (82.6), 51 (91.1), and 17 (89.5) patients in the low, normal, high BMI groups achieved remission, respectively $(P=0.553)$. After achieving remission, $8(42.1), 19(37.3)$, and 7 (41.2) patients in the low, normal, high BMI groups developed relapse, respectively $(P=0.916)$. During the observation period, 8 (34.8), 11 (19.6), and 4 (21.1) patients in the low, normal, high BMI groups required permanent dialysis therapy $(P=0.340)$. A total of 22 patients died, including $7(30.4), 13(23.2)$, and 2 (10.5) patients in the low, normal, and high BMI groups, respectively. In terms of the cause of death, 14 (63.6\%) patients died due to infection, including 7 (100), 6 (46.2), 1 (50.0) in the low, normal, high BMI groups, respectively.

\section{Discussion}

The present study revealed that low BMI at diagnosis is significantly associated with subsequent development of severe infection in elderly AAV patients in a single-center, retrospective cohort from Japan. Our results suggested that malnutrition at diagnosis might increase vulnerability to infection during immunosuppressive treatment in elderly patients, in particular. No previous study has focused on the clinical impact of underweight on infection risk in elderly AAV patients, and our results may provide a basis for identifying elderly AAV patients requiring more careful management to reduce severe infection risk.

Previously, the relationship between $\mathrm{BMI}$ and infection risk has been evaluated in several general population-based cohort studies; however, these studies did not yield consistent results according to the participant's characteristics [20]. First, in children and adolescents, underweight is considered a significant risk factor for infection in developing countries, probably reflecting malnutrition and poor 
hygiene standards [21]. On the other hand, data from industrialized countries suggest that infection rate is increased in obese children and adolescents [22]. For adults, several studies have suggested a Ushaped increase in the infection rate for both underweight and obese participants, in industrialized countries [23-25].

In terms of elderly populations, Thomas et al. studied 619 inpatient geriatric patients ( $\geq 75$ years) and showed that both underweight $\left(\mathrm{BMI}<20 \mathrm{~kg} / \mathrm{m}^{2}\right)$ and overweight $\left(\mathrm{BMl}>28 \mathrm{~kg} / \mathrm{m}^{2}\right)$ increased the risk for overall infection, including pneumonia, urinary tract infection (UTI), diarrhea, and others (incidence risk ratios: 1.84 [95\% $\mathrm{Cl} 1.40-2.42$ ] for $\mathrm{BMI}<20 \mathrm{~kg} / \mathrm{m}^{2}, 1.54$ [95\% $\mathrm{Cl} 1.07-2.22$ ] for $\mathrm{BMI}>28 \mathrm{~kg} / \mathrm{m}^{2}$ ) [26]. However, their study showed that men experienced UTIs more frequently than did women, although, among the older adults, women are usually more susceptible to UTIs than are men [27]. Although the study ascribed this to the fact that more men than women were supplied with urinary catheters, their study participants might not reflect the general population and the results should be interpreted with caution.

Additionally, a meta-analysis that included a large number of cohort studies, including 19538 nursing home residents (median age 84.3 years) revealed a higher risk of infection-related mortality (hazard ratio, $\mathrm{HR}=1.47$ [95\% $\mathrm{Cl} 1.12-1.92])$ in underweight individuals $\left(\mathrm{BMI}<18.5 \mathrm{~kg} / \mathrm{m}^{2}\right)$, and a lower risk in overweight individuals (BMI 25-29.9 kg/m²; $\mathrm{HR}=0.70[95 \% \mathrm{Cl}=0.58-0.84]$ ) and obese individuals (BMI $\geq 30 \mathrm{~kg} / \mathrm{m}^{2} ; \mathrm{HR}=0.63[95 \% \mathrm{Cl}=0.45-0.88]$ ) than the normal weight participants (BMI $18.5-25 \mathrm{~kg} / \mathrm{m}^{2}$ ) [19].

A retrospective analysis of 66820 clients (aged $>65$ years) from Elderly Health Centres in Hong Kong revealed a U-shaped relationship between BMI and influenza-associated mortality in individuals stratified by BMI groups: HR of 1.081 (95\% Cl 1.013-1.154), 1.047 (1.012-1.084), 0.981 (0.936-1.028), 1.018 (0.980-1.058), and $1.062(0.972-1.162)$, for underweight $\left(\mathrm{BMl}<18.5 \mathrm{~kg} / \mathrm{m}^{2}\right)$, normal weight (BMI 18.5$22.9 \mathrm{~kg} / \mathrm{m}^{2}$ ), overweight (BMI $23.0-24.9 \mathrm{~kg} / \mathrm{m}^{2}$ ), obese I (BMI $\left.25.0-29.9 \mathrm{~kg} / \mathrm{m}^{2}\right)$, and obese II $(B M I \geq$ $30 \mathrm{~kg} / \mathrm{m}^{2}$ ) groups, respectively [28].

However, no previous studies had focused on the association between BMI and incidence of infection in immunocompromised patients who are on immunosuppressive treatment. Therefore, it is essential to assess the clinical effect of $\mathrm{BMI}$ on infection risk in patients receiving immunosuppressive treatment. In the present study, we focused on elderly AAV patients who are at high risk for infection due to immunosuppressive therapy, and found that underweight at diagnosis was a significant predictor of the risk of severe infection.

Furthermore, previous studies $[19,26,27]$ did not assess body weight change as an important factor for diagnosing malnutrition [34]. We here assessed the impact of body weight loss in the 6 months preceding diagnosis on subsequent severe infection. We found a significant effect interaction between unintentional body weight loss exceeding $10 \%$ in the 6 months prior to diagnosis and of low $\mathrm{BMI}\left(<18.5 \mathrm{~kg} / \mathrm{m}^{2}\right)$ on the development of severe infection, suggesting that patients who were severely malnourished due to 
unintentional weight loss might be more vulnerable to immunosuppressive treatment, increasing their risk for developing severe infection.

Although the precise mechanism of the influence of BMI on the immune system is unresolved, in undernourished subjects, depleted leucocyte, lymphocyte, and T-cell counts, increased CD4/CD8 ratios, and decreased $C D 2 / C D 19$ ratios have been found $[35,36]$. In addition, several factors with immunomodulatory effects, including physical activity [37], nutritional aspects (dietary composition or supplements) [38], and well-being [39] might modulate the infection risk.

The present study had several limitations. First, because of the retrospective, observational nature of the present study, evaluation of the clinical consequences of an altered immune response could not fully adjust for confounding factors, such as the underlying immune condition or co-morbidities of each patient. In addition, the various immunomodulatory factors mentioned above could not be assessed in the present study. Further studies should investigate the impact of these factors. Second, most of our patients were elderly MPA patients from Japan; hence, the results may not be generalizable to young or middle-aged or GPA patients from other geographic areas. Third, we were unable to assess the effect of the lifetime duration of BMI and its status over the entire follow-up period on the outcomes; hence, the impact of change in BMI after starting immunosuppressive treatment could not be assessed. We believe that the potential preventive measures focusing on improving the nutritional intake of these high-risk patients should be evaluated in further studies.

In conclusion, the present study identified a lower BMI as a significant predictor of the risk of severe infection in AAV patients. This suggests that physicians should pay particular attention to AAV patients with low BMI to monitor the development of infection.

\section{Abbreviations}

AAV, antineutrophil cytoplasmic antibody-associated vasculitis

ANCA, antineutrophil cytoplasmic antibody

AZA, azathioprine

$\mathrm{BMI}$, body mass index

BVAS, Birmingham Vasculitis Activity Score

$\mathrm{Cl}$, confidence interval

CYC, cyclophosphamide

EGPA, eosinophilic granulomatosis with polyangiitis

GPA, granulomatosis with polyangiitis

Page 14/20 
HD, hemodialysis

HR, hazard ratio

MPA, microscopic polyangiitis

MPO, myeloperoxidase

mPSL, methylprednisolone

PR3, proteinase 3

RTX, rituximab

\section{Declarations}

Ethics approval and consent to participate:

The study protocol was approved by the Ethics Committees of Aichi Medical University (approval number 2018-H350, date November 3, 2019). The need to obtain patients' informed consent was waived due to the retrospective nature of the study

Consent for publication:

Not applicable

Availability of data and material:

All data were fully anonymized (Table S1).

Competing interests:

There are no conflicts of interest to declare.

Funding:

No fund.

Authors' contributions:

Conceptualization: HS, MY, TK, and SB; Methodology: HS, MY, TK, and Yl; Formal analysis and investigation: MY, and TK; Writing - original draft preparation: HS, MY, HN, and Sl; Writing - review and editing: MY, TK, SB, YI, HN, SI, HK, and TI; Supervision: MY, TK, SB, YI, HN, HK, SI, and TI. All authors read and approved the final manuscript.

Acknowledgements: 
The authors are grateful to all the medical staff who participated in this study.

\section{References}

1. Jennette JC, Falk RJ, Bacon PA, Basu N, Cid MC, Ferrario F, et al. 2012 revised International Chapel Hill Consensus Conference Nomenclature of Vasculitides. Arthritis Rheum. 2013;65:1-11. doi: 10.1002/art.37715.

2. Jennette JC, Falk RJ. Pathogenesis of antineutrophil cytoplasmic autoantibody-mediated disease. Nat Rev Rheumatol. 2014;10:463-73. doi: 10.1038/nrrheum.2014.103

3. Hogan J, Avasare R, Radhakrishnan J. Is newer safer? Adverse events associated with first-line therapies for ANCA-associated vasculitis and lupus nephritis. Clin J Am Soc Nephrol. 2014;9:165767. doi:10.2215/CJN.01600214.

4. Robson J, Doll H, Suppiah R, Flossmann O, Harper L, Höglund P, et al. Damage in the anca-associated vasculitides: long-term data from the European vasculitis study group (EUVAS) therapeutic trials. Ann Rheum Dis. 2015;74:177-84. doi: 10.1136/annrheumdis-2013-203927.

5. Mun $\mathrm{CH}$, Yoo J, Jung SM, Song JJ, Park YB, Lee SW. The initial predictors of death in 153 patients with ANCA-associated vasculitis in a single Korean centre. Clin Exp Rheumatol. 2018;36 Suppl 111:65-72.

6. Rhee RL, Hogan SL, Poulton CJ, McGregor JA, Landis JR, Falk RJ, etc. Trends in long-term outcomes among patients with antineutrophil cytoplasmic antibody-associated vasculitis with renal disease. Arthritis Rheumatol. 2016;68:1711-20. doi: 10.1002/art.39614.

7. Wallace ZS, Lu N, Miloslavsky E, Unizony S, Stone JH, Choi HK. Nationwide trends in hospitalizations and in-hospital mortality in granulomatosis with polyangiitis (Wegener's). Arthritis Care Res. 2017;69:915-921. doi:10.1002/acr.22976

8. Mohammad AJ, Segelmark M, Smith R, Englund M, Nilsson JÅ, Westman K, et al. Severe infection in antineutrophil cytoplasmic antibody-associated vasculitis. J Rheumatol. 2017;44:1468-1475. doi: 10.3899/jrheum.160909.

9. Little MA, Nightingale P, Verburgh CA, Hauser T, De Groot K, Savage C, et al. Early mortality in systemic vasculitis: relative contribution of adverse events and active vasculitis. Ann Rheum Dis. 2010;69:1036-43. doi: 10.1136/ard.2009.109389.

10. van Assen S, Agmon-Levin N, Elkayam O, Cervera R, Doran MF, Dougados M, et al. EULAR recommendations for vaccination in adult patients with autoimmune inflammatory rheumatic diseases. Ann Rheum Dis. 2011;70:414-22. doi: 10.1136/ard.2010.137216.

11. Yang L, Xie H, Liu Z, Chen Y, Wang J, Zhang H, Ge Y, Hu W. Risk factors for infectious complications of ANCA-associated vasculitis: A cohort study. BMC Nephrol. 2018;19:138. doi: 10.1186/s12882-0180933-2.

12. Yoo J, Jung SM, Song JJ, Park YB, Lee SW. Birmingham vasculitis activity and chest manifestation at diagnosis can predict hospitalised infection in ANCA-associated vasculitis. Clin Rheumatol. 
2018;37:2133-141. doi:10.1007/s10067-018-4067-5

13. Kitagawa K, Furuichi K, Sagara A, Shinozaki Y, Kitajima S, Toyama T, et al. Risk factors associated with relapse or infectious complications in Japanese patients with microscopic polyangiitis. Clin Exp Nephrol. 2016;20:703-711. doi: 10.1007/s10157-015-1199-7.

14. Faurschou M, Obel N, Baslund B. Long-term risk and outcome of infection-related hospitalization in granulomatosis with polyangiitis: a nationwide population-based cohort study. Scand J Rheumatol. 2018;47:475-480. doi:10.1080/03009742.2018.1461924

15. Booth AD, Almond MK, Burns A, Ellis P, Gaskin G, Neild GH, et al. Outcome of ANCA-associated renal vasculitis: a 5-year retrospective study. Am J Kidney Dis. 2003;41:776-84. doi: 10.1016/s02726386(03)00025-8.

16. Charlier C, Henegar C, Launay O, Pagnoux C, Berezné A, Bienvenu B, et al. Risk factors for major infections in Wegener granulomatosis: analysis of 113 patients. Ann Rheum Dis. 2009;68:658-63. doi: 10.1136/ard.2008.088302.

17. Goupil R, Brachemi S, Nadeau-Fredette AC, Déziel C, Troyanov Y, Lavergne V, et al. Lymphopenia and treatment-related infectious complications in ANCA-associated vasculitis. Clin J Am Soc Nephrol. 2013;8:416-23. doi: 10.2215/CJN.07300712.

18. Harper L, Savage CO. ANCA-associated renal vasculitis at the end of the twentieth century-a disease of older patients. Rheumatology. 2005;44:495-501. doi:10.1093/rheumatology/keh522.

19. Veronese N, Cereda E, Solmi M, Fowler SA, Manzato E, Maggi S, et al. Inverse relationship between body mass index and mortality in older nursing home residents: A meta-analysis of 19,538 elderly subjects. Obes Rev. 2015;16:1001-15. doi: 10.1111/obr.12309.

20. Dobner J, Kaser S. Body mass index and the risk of infection - from underweight to obesity. Clin Microbiol Infect. 2018;24:24-28. doi:10.1016/j.cmi.2017.02.013

21. Tembo J, Kabwe M, Chilukutu L, Chilufya M, Mwaanza N, Chabala C, et al. Prevalence and risk factors for betaherpesvirus DNAemia in children $>3$ weeks and $<2$ years of age admitted to a large referral hospital in sub-Saharan Africa. Clin Infect Dis. 2015;60:423-31. doi: 10.1093/cid/ciu853.

22. Kraft R, Herndon DN, Williams FN, Al-Mousawi AM, Finnerty CC, Jeschke MG. The effect of obesity on adverse outcomes and metabolism in pediatric burn patients. Int J Obes (Lond). 2012;36(4):485-490. doi:10.1038/ijo.2011.224

23. Harpsøe MC, Nielsen NM, Friis-Møller N, Andersson M, Wohlfahrt J, Linneberg A, et al. Body mass index and risk of infections among women in the Danish national birth cohort. Am J Epidemiol. 2016;183:1008-17. doi: 10.1093/aje/kwv300.

24. Phung DT, Wang Z, Rutherford S, Huang C, Chu C. Body mass index and risk of pneumonia: a systematic review and meta-analysis. Obes Rev. 2013;14:839-857. doi:10.1111/obr.12055.

25. Braun ES, Crawford FW, Desai MM, Meek J, Kirley PD, Miller L, et al. Obesity not associated with severity among hospitalized adults with seasonal influenza virus infection. Infection. 2015;43:56975. doi: 10.1007/s15010-015-0802-x. 
26. Dorner TE, Schwarz F, Kranz A, Freidl W, Rieder A, Gisinger C. Body mass index and the risk of infections in institutionalised geriatric patients. Br J Nutr. 2010;103:1830-5. doi:10.1017/S0007114510000152.

27. Yoshikawa TT, Nicolle LE, Norman DC. Management of complicated urinary tract infection in older patients. J Am Geriatr Soc. 1996;44:1235-41. doi:10.1111/j.1532-5415.1996.tb01376.x.

28. Yang L, Chan KP, Lee RS, Chan WM, Lai HK, Thach TQ, et al. Obesity and influenza associated mortality: evidence from an elderly cohort in Hong Kong. Prev Med. 2013;56:118-23. doi: 10.1016/j.ypmed.2012.11.017.

29. Watts R, Lane S, Hanslik T, Hauser T, Hellmich B, Koldingsnes W, et al. Development and validation of a consensus methodology for the classification of the ANCA-associated vasculitides and polyarteritis nodosa for epidemiological studies. Ann Rheum Dis. 2007;66:222-7. doi: 10.1136/ard.2006.054593.

30. Luqmani RA, Bacon PA, Moots RJ, Janssen BA, Pall A, Emery P, et al. Birmingham Vasculitis Activity Score (BVAS) in systemic necrotizing vasculitis. QJM. 1994;87:671-8.

31. Watts R, Lane S, Hanslik T, Hauser T, Hellmich B, Koldingsnes W, et al. Development and validation of a consensus methodology for the classification of the ANCA-associated vasculitides and polyarteritis nodosa for epidemiological studies. Ann Rheum Dis. 2007;66:222-7. doi: 10.1136/ard.2006.054593.

32. Yang L, Chan KP, Lee RS, Chan WM, Lai HK, Thach TQ, et al. Obesity and influenza associated mortality: evidence from an elderly cohort in Hong Kong. Prev Med. 2013;56:118-23. doi: 10.1016/j.ypmed.2012.11.017.

33. Hogan SL, Falk RJ, Chin H, Cai J, Jennette CE, Jennette JC, et al. Predictors of relapse and treatment resistance in antineutrophil cytoplasmic antibody-associated small-vessel vasculitis. Ann Intern Med. 2005;143:621-31. doi: 10.7326/0003-4819-143-9-200511010-00005.

34. Cederholm T, Jensen GL, Correia MITD, Gonzalez MC, Fukushima R, Higashiguchi T, et al. GLIM criteria for the diagnosis of malnutrition - A consensus report from the global clinical nutrition community. Clin Nutr. 2019 Feb;38(1):1-9. doi: 10.1016/j.clnu.2018.08.002.

35. Marcos A, Varela P, Toro O, Nova E, López-Vidriero I, Morandé G. Evaluation of nutritional status by immunologic assessment in bulimia nervosa: influence of body mass index and vomiting episodes. Am J Clin Nutr. 1997;66:491S-7S. doi:10.1093/ajcn/66.2.491S

36. Marcos A, Varela P, Toro O, López-Vidriero I, Nova E, Madruga D, et al. Interactions between nutrition and immunity in anorexia nervosa: a 1-y follow-up study. Am J Clin Nutr. 1997;66:485S-90S. doi: 10.1093/ajcn/66.2.485S.

37. Krüger K, Mooren FC, Pilat C. The immunomodulatory effects of physical activity. Curr Pharm Des. 2016;22:3730-48. doi:10.2174/1381612822666160322145107.

38. Urwin HJ, Miles EA, Noakes PS, Kremmyda LS, Vlachava M, Diaper ND, et al. Effect of salmon consumption during pregnancy on maternal and infant faecal microbiota, secretory IgA and calprotectin. Br J Nutr. 2014;111:773-84. doi: 10.1017/S0007114513003097.

39. Lasselin J, Alvarez-Salas E, Grigoleit JS. Well-being and immune response: a multi-system perspective. Curr Opin Pharmacol. 2016;29:34-41. doi:10.1016/j.coph.2016.05.003. 
Figures

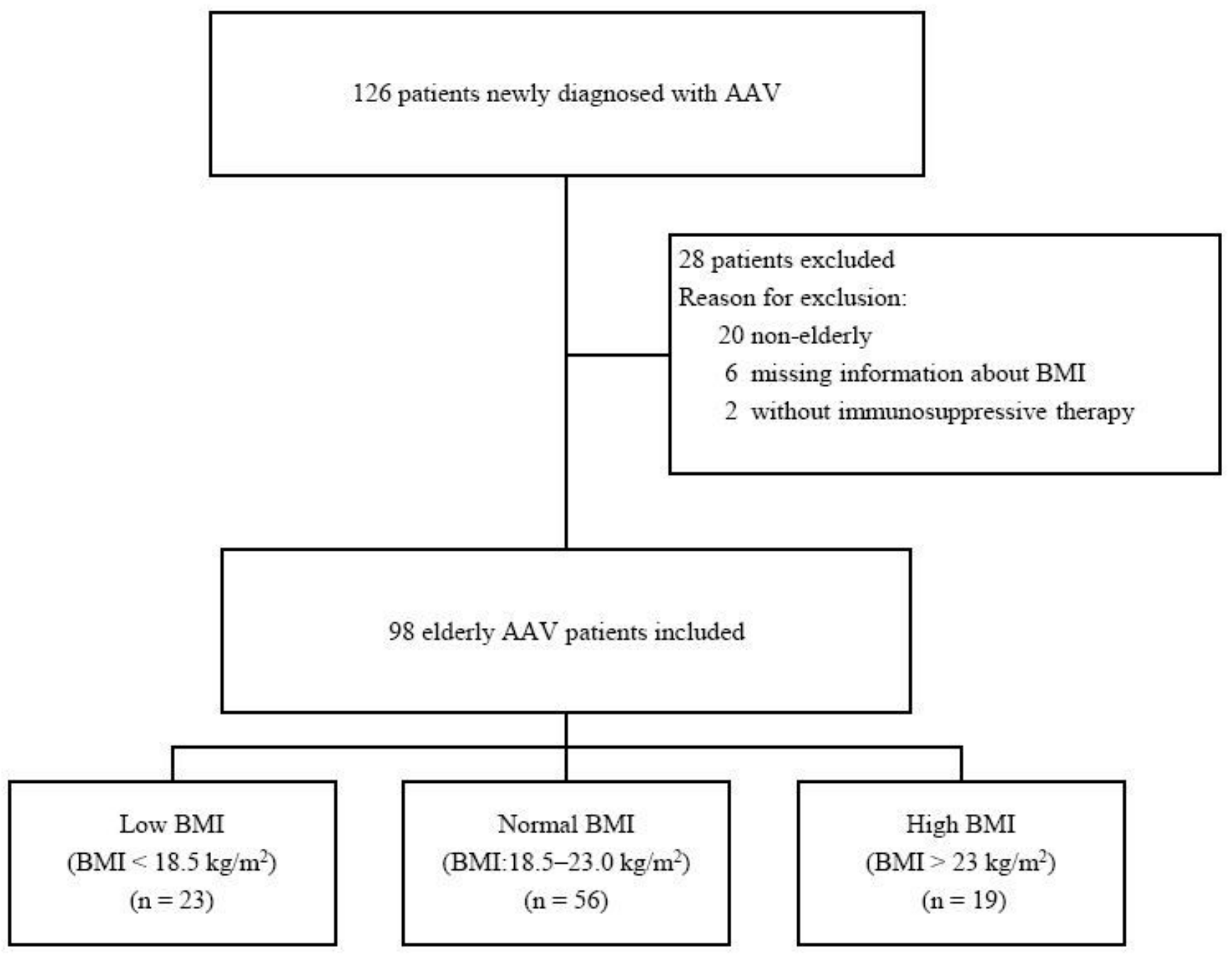

\section{Figure 1}

Flow diagram of the patient selection 


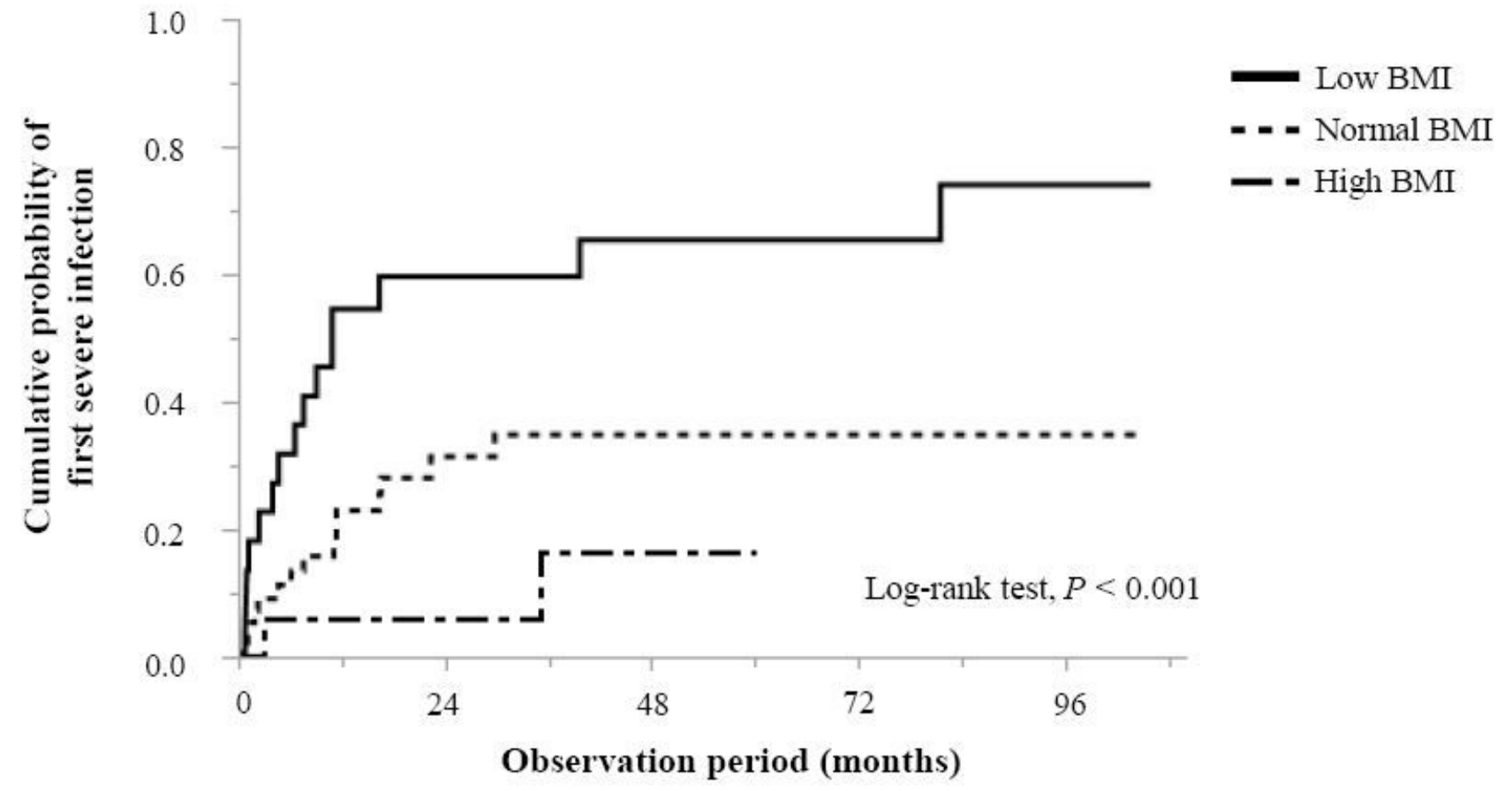

Number at risk

$\begin{array}{rrrrrr}\text { Low BMI } & 23 & 8 & 7 & 6 & 3 \\ \text { Normal BMI } & 56 & 21 & 11 & 6 & 3 \\ \text { High BMI } & 19 & 11 & 9 & 0 & 0\end{array}$

Figure 2

Cumulative probability of the first severe infection

\section{Supplementary Files}

This is a list of supplementary files associated with this preprint. Click to download.

- 20200912ANCABMIdataset.xlsx 